DEMOGRAPHIC RESEARCH

VOLUME 32, ARTICLE 58, PAGES 1581-1602

PUBLISHED 17 JUNE 2015

http://www.demographic-research.org/Volumes/Vol32/58/

DOI: 10.4054/DemRes.2015.32.58

Research Article

\title{
An assessment of recent Iranian fertility trends using parity progression ratios
}

Peter McDonald

Meimanat Hosseini-Chavoshi

Mohammad Jalal Abbasi-Shavazi

Arash Rashidian

(C) 2015 McDonald et al.

This open-access work is published under the terms of the Creative Commons Attribution NonCommercial License 2.0 Germany, which permits use, reproduction \& distribution in any medium for non-commercial purposes, provided the original author(s) and source are given credit.

See http://creativecommons.org/licenses/by-nc/2.0/de/ 


\section{Table of Contents}

1 Introduction 1582

$2 \quad$ Measurement using parity progression ratios 1584

$3 \quad$ Parity progression ratios in this study 1584

$4 \quad$ Total fertility rates derived from parity progression ratios 1556

$5 \quad$ Source of data 1557

$6 \quad$ Presentation of results 1588

6.1 Progression from marriage to first birth 1589

6.2 Progression from first to second birth 1589

6.3 Progression from second to third birth 1593

6.4 Progression from third to fourth birth 1593

6.5 Progression fourth to fifth birth 1593

6.6 Progression from fifth to sixth birth 1593

$\begin{array}{lll}6.7 & \text { Summary } & 1594\end{array}$

$7 \quad$ The trend in the proportion of women who ever marry 1594

$8 \quad$ The Total Fertility Rate 1596

9 Historical description of the Iranian fertility decline 1598

10 Conclusion 1599

$\begin{array}{ll}\text { References } & 1601\end{array}$ 


\title{
An assessment of recent Iranian fertility trends using parity progression ratios
}

\author{
Peter McDonald ${ }^{1}$ \\ Meimanat Hosseini-Chavoshi ${ }^{2}$ \\ Mohammad Jalal Abbasi-Shavazi ${ }^{3}$ \\ Arash Rashidian ${ }^{4}$
}

\begin{abstract}
BACKGROUND

In 2013 a draft population bill was introduced in the Iranian Parliament. Based on the presumption that fertility in Iran had fallen to a very low level, the bill proposed a wide range of pronatalist policies with the aim of increasing fertility to 2.5 births per woman. The draft law called for restrictions on the employment of women and young single people and inducements for women to marry in their late teens. New estimates of fertility, such as those provided in this paper, cast doubt upon the view that fertility had fallen to a very low level. In May 2014 a statement issued by the Supreme Leader provided guidelines for a more moderate approach to sustaining fertility at around the replacement level.
\end{abstract}

\section{OBJECTIVE}

To measure the trend in fertility in Iran, especially from 2000 onwards.

\section{METHODS}

Using the 2010 IDHS, the synthetic cohort parity progression ratio method is used to measure the fertility trend in Iran. Synthetic parity progressions are compared with real cohort parity progressions to examine the presence of tempo effects. Comparison is made with age-based measures from surveys, censuses, and the birth registration system.

\footnotetext{
${ }^{1}$ The Australian National University and ARC Centre of Excellence in Population Ageing Research. E-Mail: peter.mcdonald@anu.edu.au.

${ }^{2}$ The Australian National University and ARC Centre of Excellence in Population Ageing Research. E-Mail: meimanat.hosseini@anu.edu.au.

${ }^{3}$ University of Tehran and The Australian National University. E-Mail: jalal.abbasi@anu.edu.au.

${ }^{4}$ Tehran University of Medical Sciences. E-Mail: arashidian@tums.ac.ir.
} 


\section{RESULTS}

This paper demonstrates that fertility in Iran was constant for the decade 2000-2009, at a level of around 1.8-2.0 births per woman.

\section{CONCLUSIONS}

Our findings provide evidence supporting a more moderate approach to sustaining fertility in Iran at around the replacement level.

\section{COMMENTS}

The paper demonstrates the advantages of parity-based measurement over age-based measurement when tempo effects may be involved.

\section{Introduction}

Iran has experienced one of the most rapid falls in fertility ever recorded. The observed pattern is one in which fertility fell simultaneously in all age groups, in all geographic settings, and in all social groups, hence accounting for the rapidity of the decline at the national level. From a high of 7.0 births per woman in the early 1980s, fertility fell to 5.5 in 1988 and, with the introduction of the government family planning program in 1990, to 2.8 by the mid-1990s. The 2000 Iran Demographic and Health Survey (IDHS) indicated that the fertility rate declined further, reaching near-replacement level by 2000. However, some leveling off of the fertility decline near replacement level was indicated from analysis of the 2006 Census using the own-children method (AbbasiShavazi et al. 2009).

In 2011 the United Nations Population Division published its World Population Prospects: The 2010 Revision. In this report the Iranian TFR was estimated to have fallen from 1.96 in 2000-2005, a level consistent with the analysis of Abbasi-Shavazi et al. (2009), to 1.77 in 2005-2010 and to 1.59 in 2010-2015. It was then projected to fall to 1.34 by $2025-2030$ in the medium variant projection and to an extraordinarily low 0.84 in the low variant projection (Figure 1). Iran's population was projected to fall from 74.0 million in 2010 to 62.1 million in 2100 according to the medium variant and to 31.4 million according to the low variant. These numbers provided some support to already existing concerns about low fertility in parts of the then conservative Iranian Government, leading to the introduction of a draft pronatalist bill in the Iranian parliament. The draft bill, among numerous other provisions, called for restrictions on the employment of women and young single people and inducements for women to marry in their late teens. Subsequently, the United Nations Population Division revised its estimates and projections of Iran's fertility in World Population Projections: The 
2012 Revision, with fertility in the $21^{\text {st }}$ century never falling below 1.83 in the medium variant (Figure 1). While the UN, in the light of more recent data, has revised its estimates upwards substantially, there are still claims that Iran's TFR was as low as 1.5 in 2011 (Erfani 2014).

In the conclusion to our book on the fall of fertility in Iran (Abbasi et al. 2009), we speculated that economic uncertainty would lead to delay of first marriage and/or first births in the immediate future and this would produce a tempo effect leading to even lower fertility in the future. We considered that the long-held cultural beliefs that women should marry early and have their first baby soon after marriage would fade. In this paper we use data from the 2010 Iran Demographic and Health Survey to update estimates of fertility in Iran. Counter to our earlier speculation of falling fertility after 2000, we conclude that fertility in Iran was near-to-constant in the decade 2000-2010, and close to the replacement level. We conclude also that the ages at first marriage and first birth remained constant. To reduce the potential that the cross-sectional age-based total fertility rate may be affected by changes in the timing of births, especially by an observed widening of the interval between the first and the second birth (AbbasiShavazi et al. 2009), we examine fertility trends using parity progression ratios. We also examine changes in spacing for each birth interval and then the overall impact on the total fertility rate derived from parity progressions.

Figure 1: Total Fertility Rate Assumptions for Iran, United Nations Population Division, World Population Prospects, 2010 and 2012 Revisions

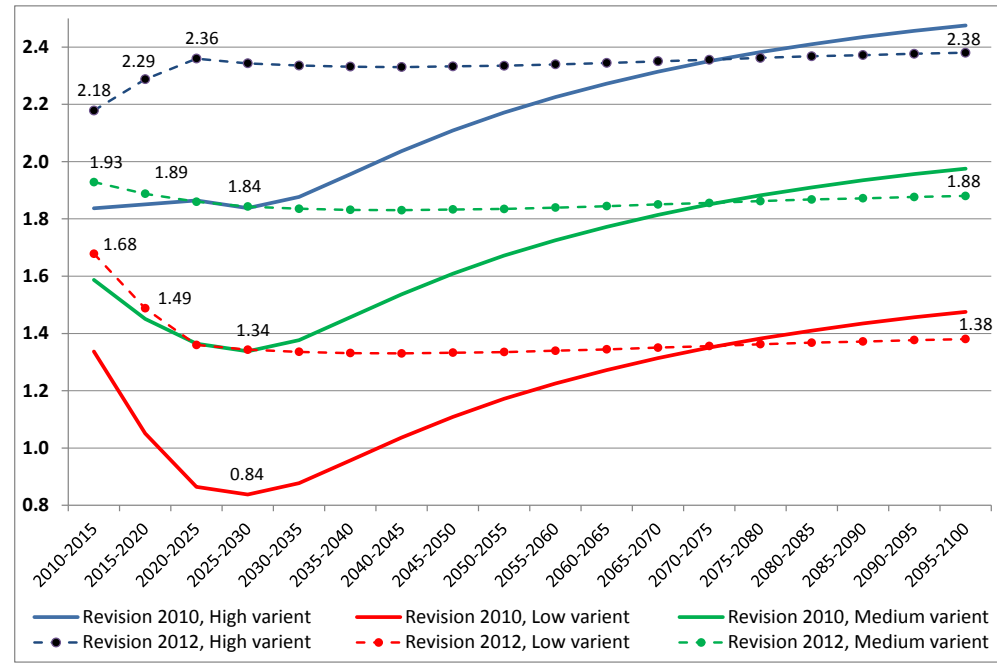

Source: UN, Dept. of Economic and Social Affairs, Population Division: World Population Prospects DEMOBASE extract. 2014. 


\section{Measurement using parity progression ratios}

The general trend for age-specific fertility rates during the period 1976-2006 was that they moved in the same direction as the total fertility rate at all ages. When the rate of fertility rose, it rose at all ages; when it fell, it fell at all ages (Abbasi-Shavazi et al. 2009). These trends have focused interpretation of the changes in fertility on the impact of cross-sectional social and political changes. However, the age-based model is not informative in relation to changes in the timing of successive births. Age-specific fertility rates and their sum, the total fertility rate, use age as a controlling or standardizing factor because the age structure of the population changes from year to year. However, age is not the only structural feature of a population that can influence the number of births in a given year. The other important structural features are the distribution of women according to the number of children that they already have, that is, their parity and the time since the most recent birth.

To better assess the impact on period fertility of changes in the timing of births, the synthetic parity progression method provides an alternative to the conventional agebased approach to the study of fertility. In this method the control used is not age but parity in association with the time since the most recent birth (Feeney 1983; Feeney and Yu 1987; Ni Bhrolchain 1987; Rallu and Toulemon 1994; Hinde 1998: Chapter 9). It is argued that analysis by parity and duration since last birth facilitates interpretation of fertility trends because people make their decisions about having a child on the basis of the number of children that they already have, rather than simply on how old they are. Duration since the last birth is a much better predictor of whether and when a woman will have her next birth than is her age (McDonald and Kippen 2011). The synthetic parity progression method has been applied successfully to a number of Asian countries, including in our previous study of Iran (Hosseini-Chavoshi et al. 2006; Spoorenberg 2010, 2013; Spoorenberg and Dommaraju 2012). The limitations of the age-based TFR and the superiority of parity-based measures have been described by Sobotka and Lutz (2009). The innovation in this paper is that we demonstrate the value of comparing results from synthetic and real cohorts using the parity progression approach.

\section{Parity progression ratios in this study}

In the literature, three main approaches to the analysis of fertility using parity have been used (Ni Bhrolchain 1987; Hinde 1998: Chapter 9): parity progression for birth or marriage cohorts, true parity cohorts, and synthetic parity progression. The current paper aims to explore the patterns and the quantum and tempo of fertility over the last 
two decades in Iran using parity progression ratios by duration since marriage or since the previous birth for both real and synthetic cohorts. As fertility outside marriage is negligible in Iran, the date of first marriage is a reliable starting point for analysis.

To derive lifetime parity progression rates for any parity, based on the literature (Feeney and Yu 1987, Ni Bhrolchain 1987) we assume that cumulated experience by the end of the 10th year after the previous birth is sufficient to approximate a lifetime. An examination of the Iran DHS data confirms that the number of births occurring ten or more years after the previous birth is negligible.

To obtain estimates for real parity cohorts, we measure the proportion of women giving birth in a given year who progress to the next birth within the following ten years. For example, for the group of women who had their first birth in 1999, we measure the proportion that had a second birth by 2009.

In the calculation of synthetic parity progression ratios, we bring together all those who had a birth of a given parity in a particular calendar year and measure the probability that they would do this given the time since their previous birth. These probabilities are then combined into a summary synthetic measure for all durations since the previous birth.

To assess the importance of quantum and tempo effects for each parity progression, we compare the progression ratios for real cohorts with the ratios for the cross-sectional synthetic cohorts. We do this by comparing the value for a real cohort with the value for the synthetic cohort four years later, on the basis that the mean duration to the next birth is around four years, irrespective of the initial parity. This comparison is illustrated in the Lexis diagram (Figure 2). This mirrors the procedure that is used to identify quantum and tempo effects in the age-based total fertility rate by plotting the real cohort value at the year of birth of the cohort plus the mean age at childbearing (usually around 27 years after the women in the cohort were born) (McDonald and Kippen 2011). In relation to the first birth, the progression from first marriage is used. In this case, however, the mean duration is only three years, and so in the comparison of the synthetic and real measures we use only a three-year gap. 
Figure 2: $\quad$ Lexis diagram depiction of the comparison of the real 1999 cohort (diagonal) with the 2003 synthetic cohort (vertical)

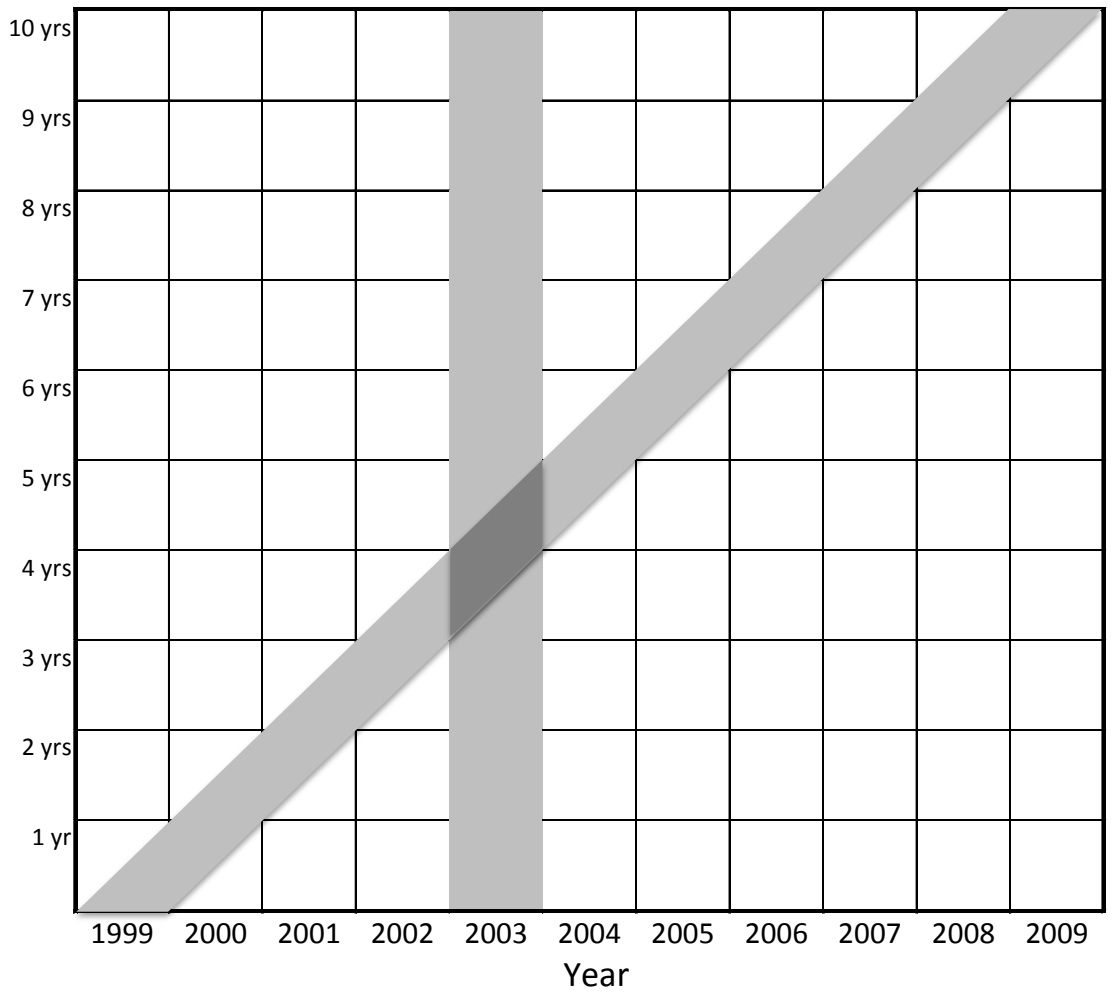

\section{Total fertility rates derived from parity progression ratios}

When births outside marriage can be assumed to be negligible, for any synthetic cohort the total fertility rate can be calculated from the combination of the progression ratios for that calendar year using a life table approach to derive the final parity distribution of the cohort and calculating the mean completed parity (see Hosseini-Chavoshi et al. 2006). This procedure also requires estimates of the proportion of the cohort that marries and of those that do not marry and are assumed to have no children. For all synthetic cohorts we assume that $10 \%$ never married. This is consistent with the estimates across time found in the synthetic percentages never marrying, as described 
later in the paper. Progressions to the ninth and higher-order births were not included, so the calculated total fertility rates are slightly underestimated.

We have also derived a total fertility rate from the real cohort parity progressions. We do this by combining the parity progressions for real parity cohorts that began their experience in the same calendar year. For example, taking 1999 as the calendar year of commencement, we have estimates of the proportion that progress from marriage to the first birth between 1999 and 2009, the proportion that progress from the first birth to the second birth in the same time period, and so on. These progressions can be combined in the same way as just described for synthetic cohorts to produce a total fertility rate, again assuming for all cohorts that $10 \%$ never marry. The resultant total fertility rate is the rate that would result if a marriage cohort of women experienced the real cohort parity progressions throughout their lives that applied across the given 10-year time period.

We compare the two total fertility rates (synthetic parity progressions derived from one calendar year and synthetic based on real cohort parity progressions), again with a four-year interval, as shown in Figure 1. Our contention is that each individual real cohort parity progression is free of tempo effects (variations due only to changes in the timing of births). Thus, when the real cohort progressions are combined into a total fertility rate, that rate will also be relatively free of tempo effects. Hence the comparison of the two total fertility rates will provide an indication of the extent to which the annual synthetic measure is affected by tempo rather than quantum. This enables us to assess the reliability of the most recent annual synthetic cohort total fertility rates, the most recent aggregate measures of fertility that are available.

\section{Source of data}

The source of data for this paper is the 2010 Iran Multiple-Indicators Demographic and Health Survey (IDHS). Conducted in 2010, the survey is composed of a representative sample of households throughout the country (Ministry of Health and Medical Education 2010). The sample included 31,350 households with a 94.4\% response rate (optimized for the proportions of households in urban and rural areas). Systematic cluster sampling was utilized to randomly select 10 households in each cluster. A structured supervision program and vertical training were undertaken to guarantee the quality of the data collection. The interviewers contacted 35,305 women aged 15-54 and were able to complete interviews with $98 \%$ of eligible women $(34,438)$. Three cases were dropped from the analysis due to inconsistent information in their birth histories. After weighting, the cases available for analysis numbered 35,839. 
Household data, including date of birth and marital status, are available for all members of each household. Information on reproductive behavior is obtained for all ever-married women aged 15-54, including the timing of all live births. This information and the very large size of the sample allowed us to calculate parity progression probabilities for each calendar year from 1980 to 2010 by parity and single year of duration from the previous birth.

\section{Presentation of results}

For each birth interval, we show the synthetic parity progression ratio for the years 1990-2009. The value for the real parity progression ratio for the cohort that had its previous birth $\mathrm{M}$ years before the year to which the synthetic value applies is plotted against the same year as the synthetic value. $M$ is three years for the progression from marriage to the first birth and four years for all other progressions. We also compare the mean duration of the birth interval for both real and synthetic cohorts with the same lag or gap. The analysis shows that the mean duration widens for most birth intervals across the years of comparison due to changes in the spacing of births in Iran. However, with the exception of the interval between marriage and first birth, for which the average interval for the 20 years is about three years, all the other Iranian birth intervals average out across time at about four years, thus explaining our choice of the values of M.

Where the real and the synthetic progressions overlap, we conclude there is little or no tempo effect. In these circumstances we expect to see that the mean duration curves for the synthetic and real cohorts also overlap. In the period when birth spacing widened, the 1990s, we expect to see a tempo effect due to the delay of births. This will mean that the synthetic parity progression ratio should be lower than the real parity progression ratio. The reverse is implied for the mean durations: we expect that the real mean duration between births will be lower than the synthetic mean duration.

Analysis was carried out for progressions up to and including the progression from the seventh to the eighth birth. In the following pages we show the results for the progression from marriage to first birth to the progression from the fifth to the sixth birth. The results for the progressions from the sixth to the seventh birth and the seventh to the eighth birth are very similar to those for the progression from the fifth to the sixth birth. The real and synthetic cohort trend for the parity progression ratios and the mean durations of intervals are shown in Figures 3-14. The extent of annual fluctuations provides an indicator of statistical reliability. 


\subsection{Progression from marriage to first birth}

A three-year lag between the real and synthetic cohorts is used for this interval. For real cohorts, the progression from marriage to the first birth has leveled out at a value of 0.95 (Figure 3). For the 13-year period where the real and synthetic cohorts overlap, there is close agreement between the two trends. On this evidence we would expect that the synthetic cohort trend is a reliable predictor of the future path of the real cohort trend. The synthetic rates fluctuate but show little change in their average level over the period 1995-2009. For example, the 2005 level was slightly higher than the 1995 level. This suggests that this progression will remain around 0.94 into the future.

The two curves for the mean duration of the interval between marriage and first birth overlap very closely (Figure 4). Taking the two together, this interval increases gradually by one year between 1983 and 2009. This gradual increase seems to produce very little tempo effect, as the real and synthetic parity progressions overlap closely. From about 2004 there was no further widening of this interval.

\subsection{Progression from first to second birth}

For this progression and all subsequent progressions we use a four-year lag based on the average duration across the 30 years of observation. The progression falls from close to one for the first real cohort (first birth in 1980, plotted at 1984) to close to 0.8 for the 1999 real cohort (plotted at 2003). The mean birth interval widened considerably in the 1990s (from three to five years). During the 1990s, as expected, there is evidence of a small tempo effect in the mean duration as the synthetic cohort runs ahead of the real cohort. The spacing increase slowed considerably around the beginning of the 2000s, ending the tempo effect in the mean duration trend. However, the small tempo effect caused by increased spacing did not convert into a noticeable tempo effect in the progression trend. From 2005 onwards the synthetic progression seems to have flattened out at about the same level already reached by the real cohorts $(0.80)$. The expectation is that the real progression will continue at this level into the future. 
Figure 3: Progression: Marriage to Figure 4: Mean duration: Marriage $1^{\text {st }}$ birth to $1^{\text {st }}$ birth (years)
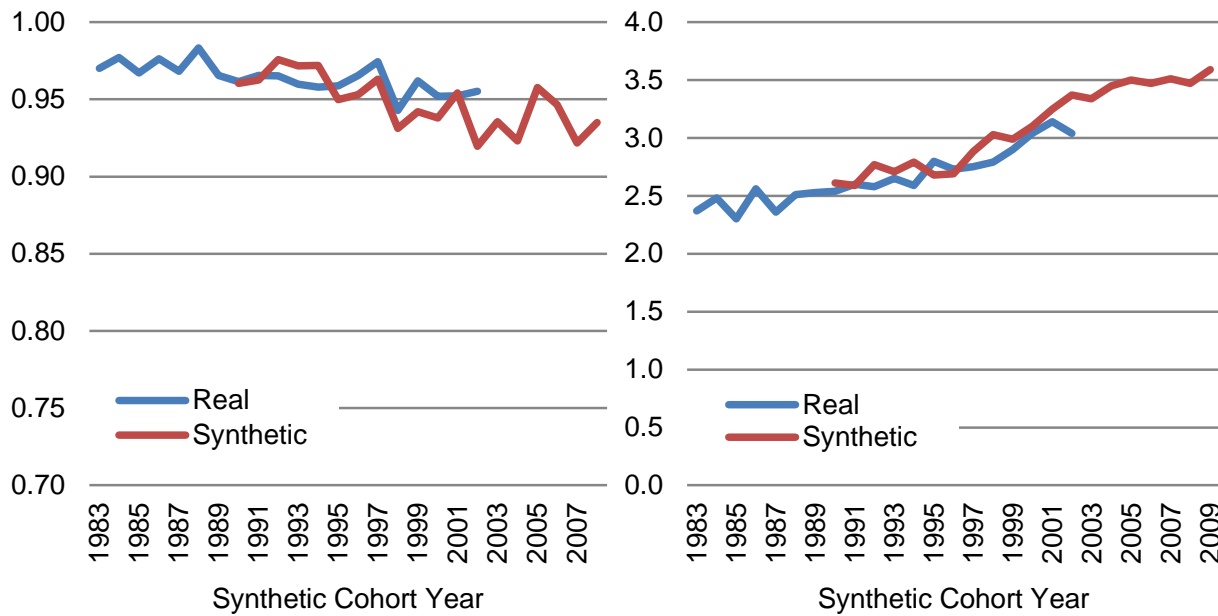

Synthetic Cohort Year

Figure 5: Progression: $1^{\text {st }}$ birth to $2^{\text {nd }}$ Figure 6: $\quad$ Mean duration: $1^{\text {st }}$ birth to birth

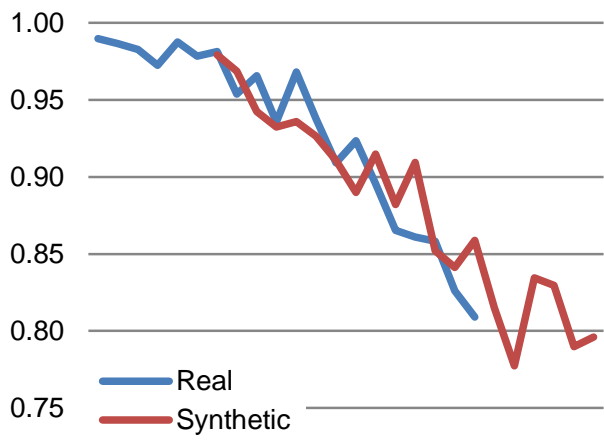

0.70

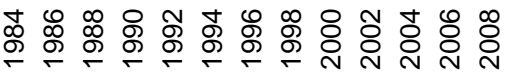

Synthetic Cohort Year

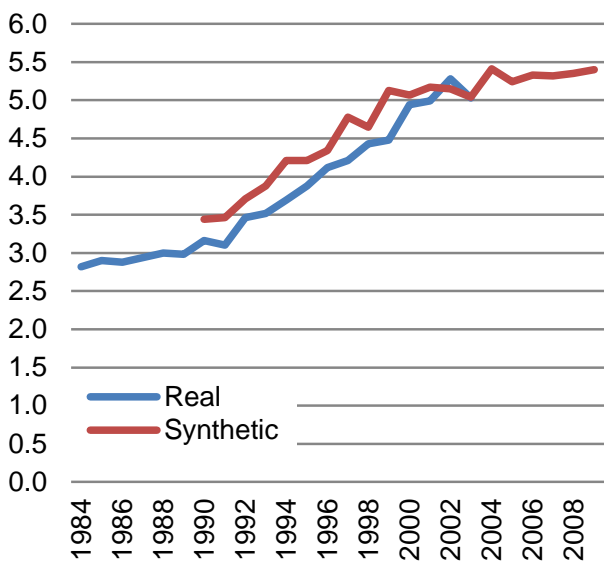

Synthetic Cohort Year 
Figure 7: Progression: $2^{\text {nd }}$ birth to $3^{\text {rd }}$ Figure 8: Mean duration: $2^{\text {nd }}$ to $3^{\text {rd }}$ birth
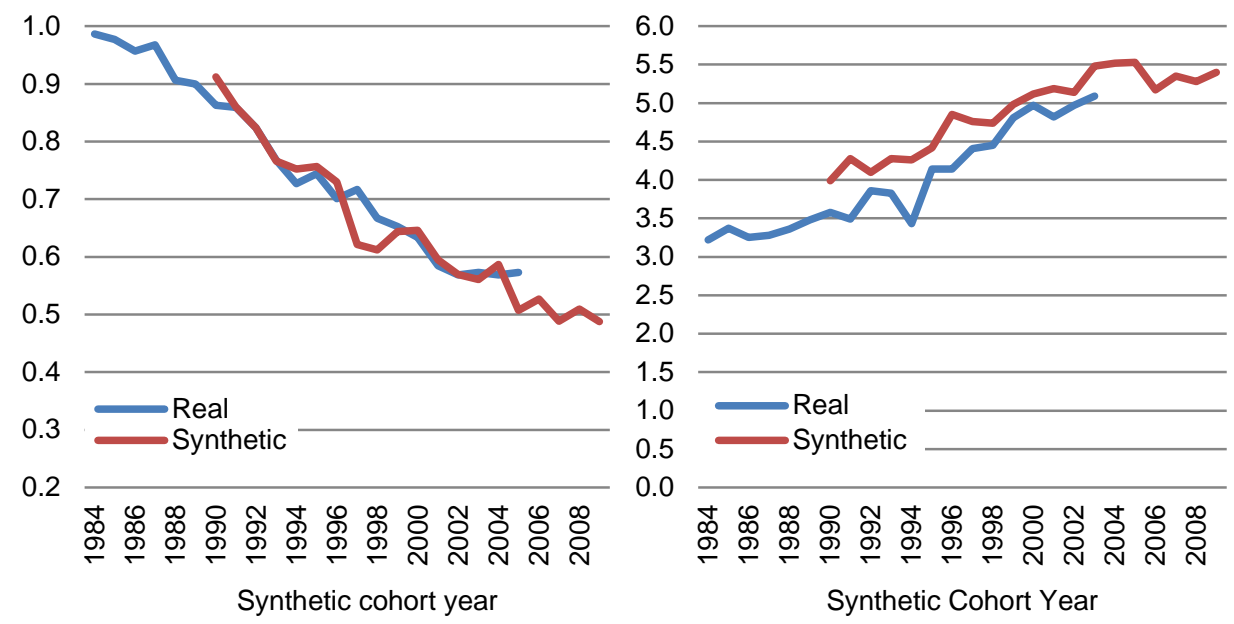

Figure 9: Progression: $3^{\text {rd }}$ birth to $4^{\text {th }}$ Figure 10: Mean duration: $3^{\text {rd }}$ to $4^{\text {th }}$ birth
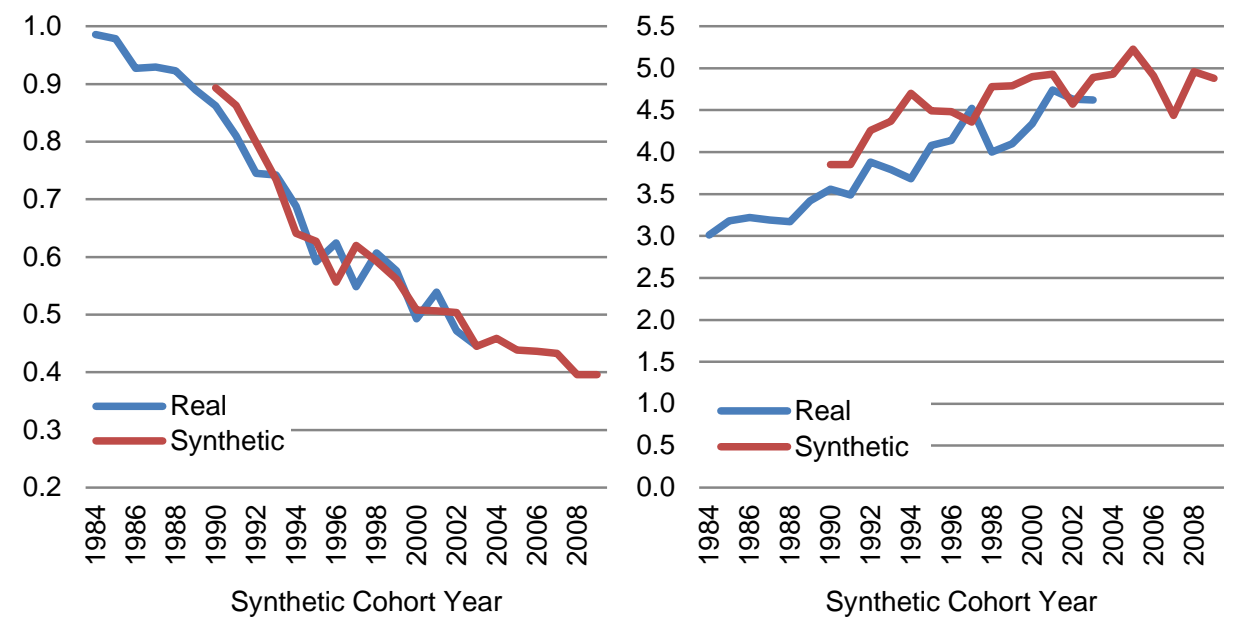


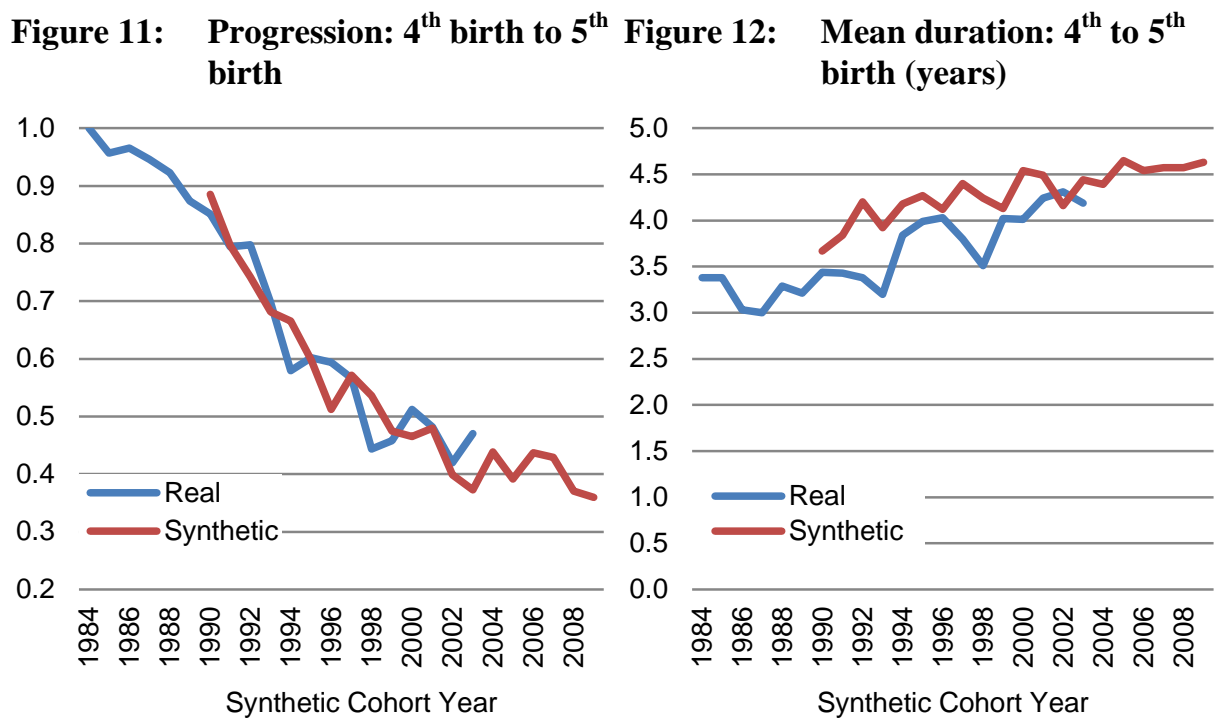

Figure 13: Progression: $5^{\text {th }}$ birth to $6^{\text {th }}$ Figure 14: Mean duration: $5^{\text {th }}$ birth to birth

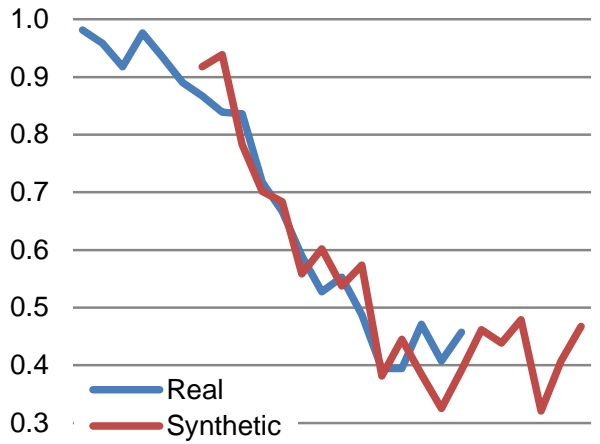

0.2

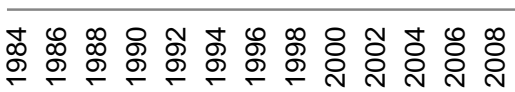

Synthetic Cohort Year

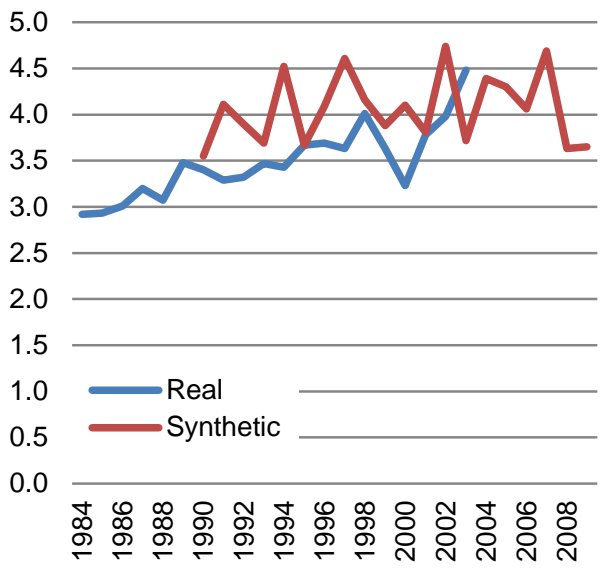

Synthetic Cohort Year 


\subsection{Progression from second to third birth}

The second to third progression falls from close to one for the first real cohort (second birth in 1980) and, given the overlap of the trends for the real and synthetic cohorts, is likely to fall to 0.5 , the level at which the synthetic cohort stabilized in the years 20052009. Again, there is a sizeable increase in the mean birth interval (close to two years), which commences from the beginning of the series and continues to the early 2000s, after which it levels off. Again, a small tempo effect is evident for the mean duration trend in the 1990s but does not produce a noticeable tempo effect in the progression trend.

\subsection{Progression from third to fourth birth}

The fall in the parity progression is even larger for the third to fourth birth progression, from close to one for the 1980 real cohort to 0.4 for the most recent synthetic cohort (2009). Once more, the mean duration increases by almost two years between the late 1980s and the early 2000s but levels off from about 2003. The fall in the parity progression seemed to have almost ceased by 2009 and we could expect a progression of 0.4 into the future.

\subsection{Progression fourth to fifth birth}

The progression from the fourth to the fifth birth falls from one for the 1980 real cohort and stabilizes around 0.4 for the synthetic cohort from about 2002 onwards. The progression for the real cohort has also leveled off in the most recent years available. The mean duration has increased continually for the real cohort from about 3.5 years to 4.5 years over the 20-year period, with no further increase since the early 2000s. The best estimate for the future is that this progression will remain at 0.4 .

\subsection{Progression from fifth to sixth birth}

The progression from the fifth to the sixth birth fell from close to one for the 1980 real cohort to 0.4 by the latter part of the 1990s and has remained unchanged for about the past 10 years of synthetic cohorts and the last five years of real cohorts, although it has fluctuated because of small numbers in the sample. For the synthetic cohort there is little evidence of change in the mean duration across the full 20 years, although the 
trend for the real cohorts suggests that this interval may have widened a little in the early 1980s.

\subsection{Summary}

For all parity progressions there is strong evidence of stability in the periods 2004-2009 and 2003-2009 and strong evidence of stability in the mean duration of birth intervals. This provides no support to the proposition that Iran's fertility fell considerably after 2005. However, it is necessary to also examine trends in marriage behavior.

\section{The trend in the proportion of women who ever marry}

Interpretation of the trend in the proportion who ever marry is more difficult to specify because, like the age-based TFR, the real and the synthetic cohorts are separated by a long period of time, essentially, on average, the mean age at marriage. In the case of Iran, this is about 20 years. Derived from single-year of age probabilities of first marriage, the synthetic measure of the proportion ever marrying fluctuated in the period 1987 to 2009 between levels of 97\% (1991) and 86\% (2002) (Figure 15). There seems to have been a slight downward trend in the 1990s, followed by a rising trend in the 2000s. As described below, these trends are consistent with the changes in age at first marriage in these years. The real cohort measure shows a declining trend, falling from about $96 \%$ for the cohort born in 1967 to $90 \%$ for the cohort born in 1975. It is difficult to be as definite about the future trend as it was in the case of the parity progressions, but the rise in the synthetic proportion in the 2000s suggests that the proportion marrying for real cohorts will tend to stabilize at around 0.9. This is also supported by the evidence that the percentages never married by age for real cohorts (Figure 16) suggest relative stability in age at first marriage for cohorts born from 1981 onwards. Indeed, counter to the assumption underlying the draft population bill and our own earlier speculation of rising age at first marriage, age at first marriage was slightly younger for the 1986 birth cohort compared with the 1981 cohort. This finding is confirmed by the census data shown in Table 1, with the percentages never married falling at the younger ages between the 2006 and 2011 censuses. A slightly earlier age at first marriage and relative constancy of the time between marriage and first birth are the central reasons that cross-sectional fertility in Iran did not fall in the 2000s. It seems, therefore, that the traditional practice of relatively early marriage followed relatively quickly by first birth continues to have force. 
Table 1: $\quad$ Percentages never married, females, age groups 15-19, 20-24, and 25-29, censuses of Iran 1976-2011

\begin{tabular}{llcc}
\hline Year & $\mathbf{1 5 - 1 9}$ & \% Never Married & \\
& 65.7 & $\mathbf{2 0 - 2 4}$ & $\mathbf{2 5 - 2 9}$ \\
\hline 1976 & 66.5 & 21.4 & 6.8 \\
1986 & 81.4 & 20.4 & 9.4 \\
1996 & 83.1 & 39.3 & 14.8 \\
2006 & 78.9 & 49.7 & 24.1 \\
$\mathbf{2 0 1 1}$ & & 48.1 & 28.2 \\
\hline
\end{tabular}

Figure 15: Progression: Birth to first marriage (20-year lag between real and synthetic)

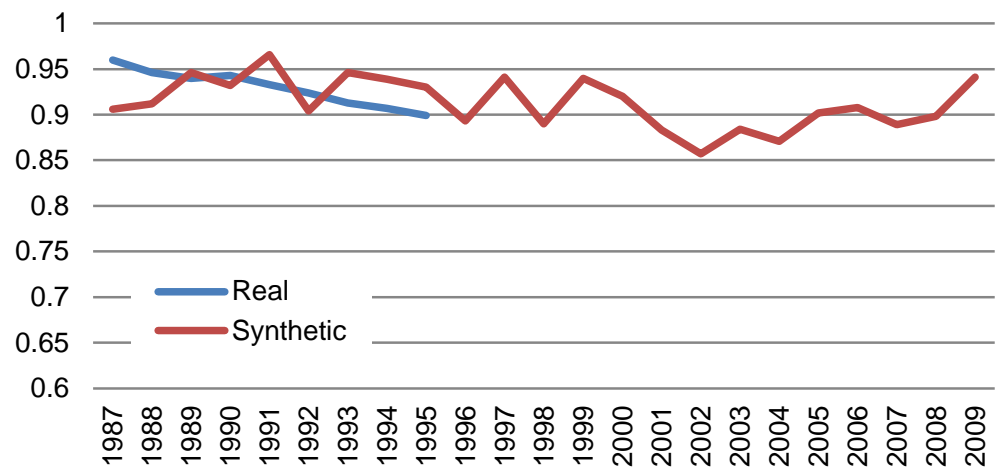

Synthetic Cohort Year

Figure 16: Proportion never married by age, real birth cohorts

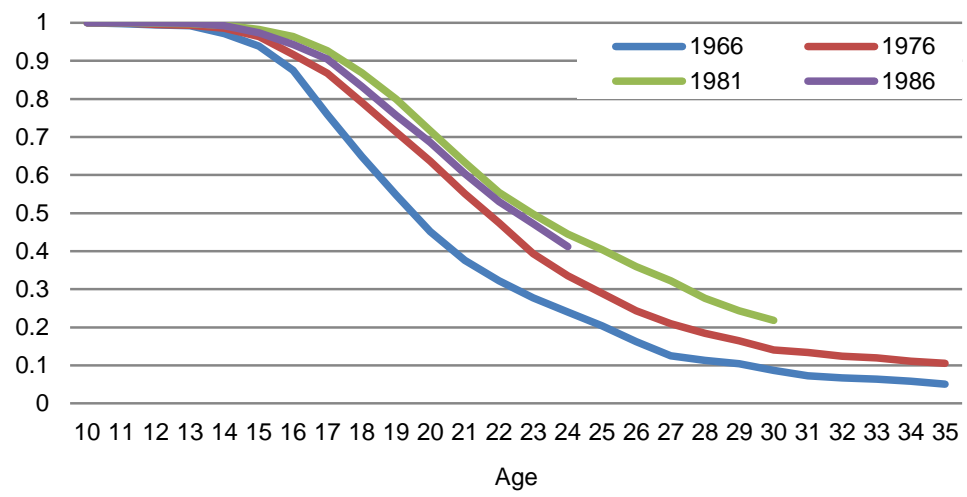




\section{The Total Fertility Rate}

Both the real and synthetic parity progression ratios can be converted to total fertility rates as described above (see also Hosseini-Chavoshi et al. 2006). As already explained, the total fertility rate that results from the combination of the real parity progressions in a given 10-year period are not 'real' in the sense that they represent the lifetime experience of a marriage cohort. Instead, it is the total fertility rate that would result if a marriage cohort of women experienced the real cohort parity progressions throughout their lives that applied at each parity in the given 10-year time period. We contend that the total fertility rate measured in this way will be relatively free of tempo effects and comparison of the two total fertility rates (synthetic and real-based) will provide an indication of the extent to which the annual synthetic measure is affected by tempo rather than quantum. This enables us to assess the reliability of the most recent annual synthetic cohort total fertility rates.

The synthetic and real-based total fertility rates are compared in Figure 17 with a four-year interval between them, the mean of all birth intervals (as depicted in Figure 2). The broad conclusion to be drawn from the comparison is that the synthetic TFR and the real-based TFR do not differ. This suggests that the synthetic measure is not distorted by tempo effects and therefore provides a highly reliable estimate of the future level of the real-based measure. Figure 17 shows that the synthetic Total Fertility Rate leveled off at about 2.0 births per woman over the years 2005-2009. As all the components of the TFR (the progression ratios) had also leveled off in this period, the best prediction of future fertility in Iran is that it will hover around replacement level into the immediate future.

Figure 17: Total Fertility Rate, Iran, 1984-2009

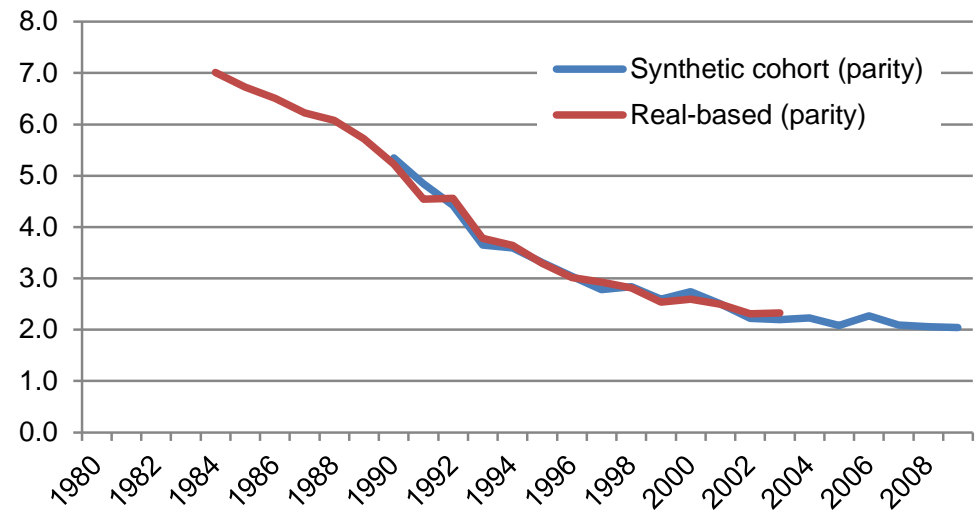


Figure 18: Total Fertility Rate, Iran, 1990-2009

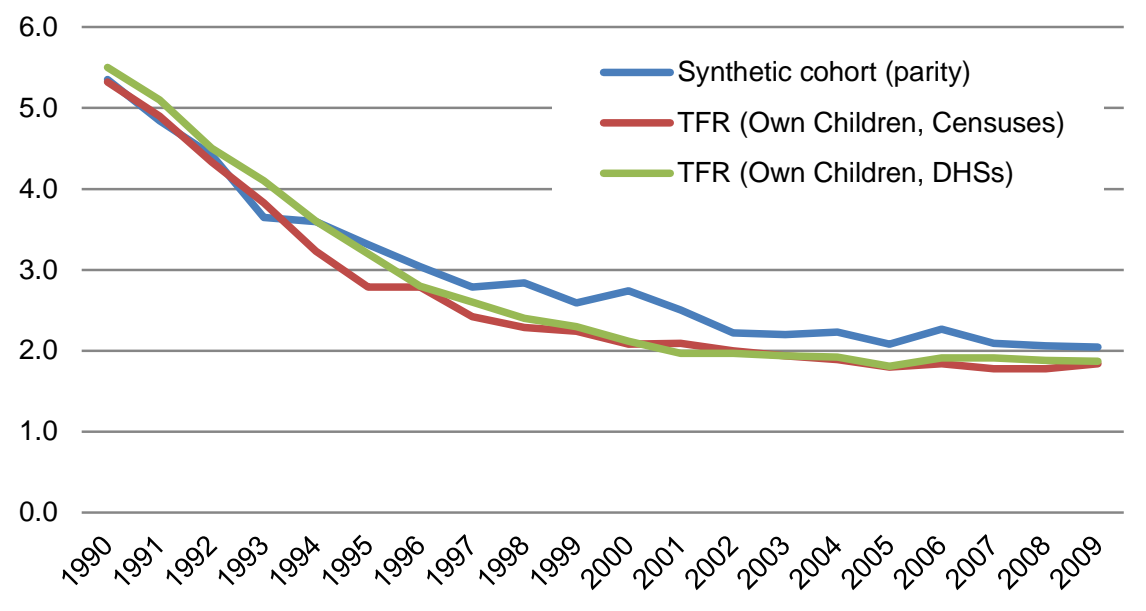

The conventional age-based Total Fertility Rate can be calculated from the Iranian censuses in 2006 and 2011 and from the household records from the 2010 Iranian DHS using the own-children method. These are compared with the synthetic cohort paritybased TFR in Figure 18 for the years 1990 to 2009. The two curves based on the ownchildren method are very similar to each other, at least from 1996 onwards, but are a little lower than the synthetic cohort parity TFRs. Importantly, however, all three curves show that fertility in Iran has remained largely unchanged since 2002 at a level around the replacement level. The own-children estimate from the DHS was 1.87 in 2009. The TFR calculated from age-specific fertility rates derived from the DHS pregnancy history data was 1.84 for the years 2005-2009, but it is considered that infants that died very quickly after birth tend to be omitted from women's reports of their pregnancy history. Avery et al. (2013) have argued that the own-children estimates of fertility from the household records of DHS surveys may be more reliable than estimates based on pregnancy histories in the same survey because DHS surveys are more likely to interview higher fertility women. This does not appear to have been the case in the Iranian DHS.

Another source of information is Iran's vital registration system, now considered by the Civil Registration Organization to be near complete in respect of births. Using the 2011 Census as a source for the numbers of women by age, the TFRs based on birth registration were 1.87 in 2009 and 1.85 in 2010 and 2011 (Abbasi-Shavazi et al. 2013).

In summary, a conclusion can be drawn that fertility in Iran was near-to-constant from 2002 to 2009 at a level of around 1.8-2.0 births per woman. There is no evidence 
that fertility fell as low as 1.5 births per woman or that Iranian fertility can be expected to fall to such a level in the immediate future.

\section{Historical description of the Iranian fertility decline}

Another conclusion to be drawn from the above analysis is that the synthetic parity progression ratios provide a good basis for describing the historical decline in fertility in Iran in terms of parity progressions (Figure 19, method explained in HosseiniChavoshi et al. 2006). Changes in the progressions to marriage and to the first birth played little part in the spectacular Iranian fertility decline, together accounting for a fall of only about 0.5 of a birth between 1990 and 2009. Changes in progressions from the fourth birth onwards played almost no role. Almost all the decline is accounted for by changes in the progressions to the second, third, and fourth births, which together account for a fall of about 2.7 births per woman. The effect in the early years of the family planning program was strongest for the progressions from the second to third birth and the third to the fourth birth. However, Figure 19 shows that there was little change in any of the effects from 2002 onwards.

Figure 19: Decomposition of the fall in fertility in Iran from 1990 to 2009 into components due to each parity progression, based on synthetic cohort parity analysis

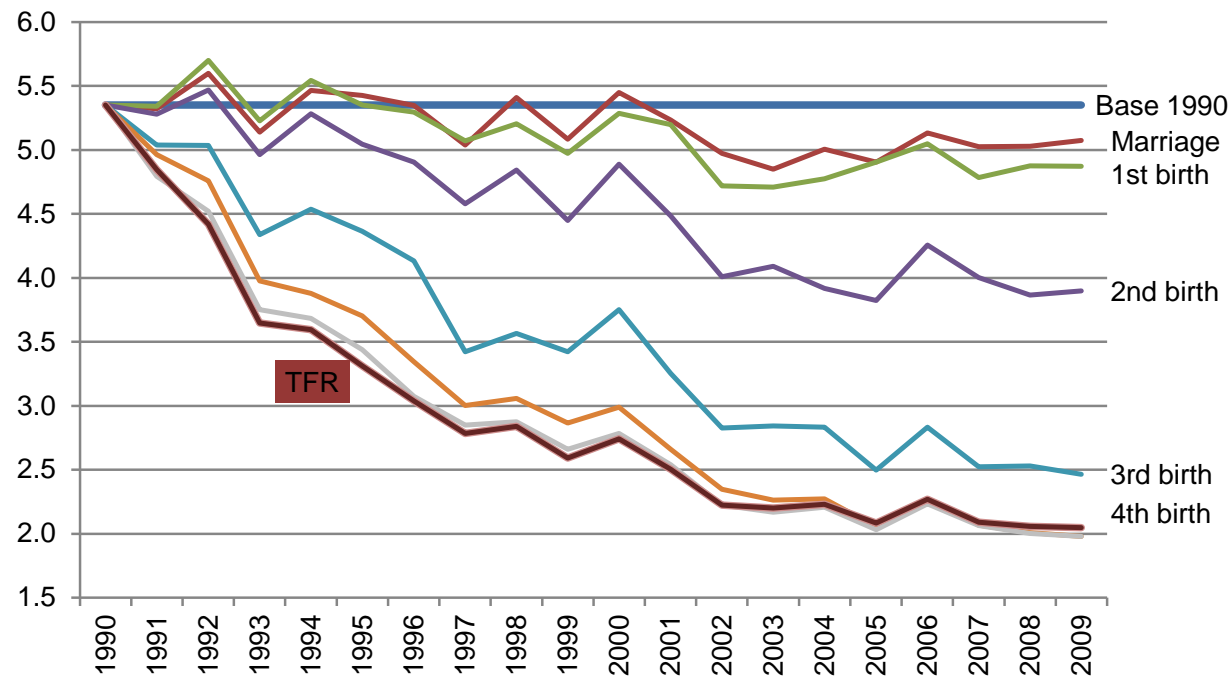


For the most recent synthetic cohort (2009) the distribution across completed parities is quite wide: $33.7 \%$ had fewer than two births, $34.1 \%$ had two births, and $32.2 \%$ had three or more births (Table 2). This partly reflects the continuing regional variations in fertility.

Table 2: Completed parity distribution of Iranian women based on the 2009 synthetic parity cohort (average of 2.01 births per woman)

\begin{tabular}{|c|c|c|c|c|c|c|c|c|c|}
\hline \multirow{2}{*}{\multicolumn{2}{|c|}{ Never Married }} & \multicolumn{8}{|c|}{ Final Number of Children for Ever Married Women } \\
\hline & & 0 & 1 & 2 & 3 & 4 & 5 & $6+$ & Total \\
\hline$\%$ & 10.2 & 6.5 & 17.0 & 34.1 & 19.6 & 8.2 & 2.5 & 1.9 & 100.0 \\
\hline
\end{tabular}

\section{Conclusion}

The analysis has shown how comparison of real and synthetic parity progression ratios can enhance understanding of a society's fertility history in terms of tempo and quantum and how it can clarify the most recent trends in fertility. The approach capitalizes on the argument that parity in combination with duration since the previous birth are much better predictors of when and whether a woman will give birth than is her current age. Of course, adding age as a third component would further enhance the accuracy, but this requires an exceptionally large sample in order to avoid small cell sizes. In application to Iran, the method is also enhanced by the fact that the number of births outside marriage is negligible and that the progression from marriage to first birth is near universal and relatively rapid. In the absence of change in age at marriage - as seems to have been the case in Iran in recent years - this means that the age distribution at first birth and its incidence is near to constant. Variations in fertility are then dependent only on the well-measured inter-birth parity progression ratios. In these circumstances the total fertility rates for 'real-based' and synthetic marriage cohorts can be compared conveniently, and in the Iranian case the most recent synthetic rate appears to be a good predictor of the future real rate.

Interestingly, there was some evidence of small tempo effects in the synthetic measures of mean durations of birth intervals, but these effects were not sufficiently large to produce tempo effects in each of the parity progressions, and hence in the total fertility rate. This tends to support the argument made by McDonald and Kippen (2011) relating to the case of Australia, that tempo effects are dominated by changes that occur in the age at first birth. In the Iran case, at least in recent times, there has been very little change in the age at first birth. The analysis gives no support to the concern that fertility in Iran has tumbled to 1.5 births per woman. 
Since this paper was first presented at the IUSSP International Population Conference in Busan in August 2013, the debate in Iran about the draft bill has progressed. The bill is still before the parliament but is now being debated in the context of a statement by the Supreme Leader, Ayatollah Ali Khamenei, issued on 30 May 2014. Where the draft bill provides a specific target fertility rate of 2.5 births per woman, the Supreme Leader's statement is more moderate, stating that fertility should be increased "to a higher rate than the rate of sub-replacement fertility". There is no reference in the statement to any sub-group of the population being favored in job allocation; instead the statement encourages the improvement of the employment prospects of all the working population. The statement does not recommend the curtailment of family planning services but is supportive of improvements in the delivery of reproductive health. However, the statement still encourages "youth to marry at a younger age" (Population and Development Review 2014). There are no time lines in the statement as there were in the draft bill. It is also evident that the fiscal implications of the draft bill are unsustainable in the current strained economic situation in Iran.

Our findings support the view that there is no need for Iran to introduce some of the more severe measures proposed in the draft population law such as discrimination against single people or women in the labor market, and that Iran has time to implement family support policies in order to sustain fertility near the replacement level. Research in Europe has shown that employment insecurity for young people has a negative effect on their fertility and on couple formation (see, for example, Lundstrom and Andersson 2012). The Iranian Government should be looking for policy measures that enhance the incomes of young people. With a greater sense of security, young people are more likely to marry and have children. Within the fiscal constraints, the focus of policy should be upon family support measures, several of which are included in the draft law, and upon policies that enable couples to balance work and family. 


\section{References}

Abbasi-Shavazi, M., Hosseini-Chavoshi, M., . Banihashemi, F., and Khosravi, A. (2013). The own-children estimates of fertility applied to the 2011 Iran Census and the 2010 Iran-MIDHS: An evaluation. Paper presented at the XXVII IUSSP International Population Conference, Busan, Republic of Korea, 26-31 August.

Abbasi-Shavazi, M., McDonald, P., and Hosseini-Chavoshi, M. (2009). The fertility transition in Iran: Revolution and reproduction. Dordrecht: Springer. doi:10.1007/978-90-481-3198-3.

Avery, C., St. Clair, T., Levin, M., and Hill, K. (2013). The “Own Children” fertility estimation procedure: A reappraisal. Population Studies 67(2): 171-183. doi:10.1080/00324728.2013.769616.

Erfani, A. (2014). Low fertility intention in Tehran, Iran: The role of attitudes, norms and perceived behavioural control. Paper presented to the 2014 Annual Meeting of the Population Association of America, Boston, MA, May 1-3.

Feeney G. (1983). Population dynamics based on birth intervals and parity progression. Population Studies 37(1): 75-89. doi:10.1080/00324728.1983.10405925.

Feeney, G. and Yu, J. (1987). Period parity measures of fertility in China. Population Studies 41(1): 77-102. doi:10.1080/0032472031000142546.

Hinde, A. (1998). Demographic methods. London: Arnold.

Hosseini-Chavoshi, M., McDonald, P. and Abbasi-Shavazi, M. (2006). The Iranian fertility decline, 1981-1999: An application of the synthetic parity progression ration method. Population 61(5): 707-718. doi:10.3917/pope.605.0701.

Lundstrom, K.E. and Andersson, G. (2012). Labour market status, migrant status, and first childbearing in Sweden. Demographic Research 27(25): 719-742. doi:10.4054/DemRes.2012.27.25.

McDonald, P. and Kippen, R. (2011). Forecasting births. Canberra: Australian Bureau of Statistics. URL: http://www.abs.gov.au/ausstats/abs@.nsf/Latestproducts/ 2051.0Feature\%20Article22006?opendocument\&tabname=Summary\&prodno=2 051.0\&issue $=2006 \&$ num $=\&$ view $=$

Ministry of Health and Medical Education. (2010). I.R. Iran Demographic and Health Survey. Tehran: Ministry of Health and Medical Education. 
McDonald et al.: An assessment of recent Iranian fertility trends using parity progression ratios

Ni Bhrolchain, M. (1987). Period parity progression ratios and birth intervals in England and Wales, 1941-1971: A synthetic life table analysis. Population Studies 41(1): 103-125. doi:10.1080/0032472031000142556.

Population and Development Review. (2014). Ayatollah Ali Khamenei on Iran's Population Policy. Population and Development Review 40(3): 573-575. doi:10.1111/j.1728-4457.2014.00708.x.

Rallu, J. and Toulemon, L. (1994). Period fertility measures: The construction of different indices and their application to France, 1946-89. Population 6: 59-93.

Sobotka, T. and Lutz, W. (2009). Misleading policy messages from the period TFR: Should we stop using it? European Demographic Research Papers 4.

Spoorenberg, T. (2010). Fertility transition in India between 1977 and 2004: Analysis using parity progression ratios. Population 65(2): 315-331. doi:10.3917/pope. 1002.0313.

Spoorenberg, T. (2013). An evaluation of the recent fertility changes in Afghanistan: A parity-specific analysis. Journal of Population Research 30(2): 133-149. doi:10.1007/s12546-013-9107-z.

Spoorenberg, T. and Dommaraju, P. (2012). Regional fertility transition in India: An analysis using synthetic parity progression ratios. International Journal of Population Research Volume 2012: 1-20. doi:10.1155/2012/358409. 